\section{PAISAJES AGRARIOS PREHISTÓRICOS EN LA MESETA PENINSULAR: EL CASO DE «LAS MATILLAS» (ALCALÁ DE HENARES, MADRID)}

\author{
PREHISTORIC AGRARIAN LANDSCAPES \\ IN THE IBERIAN MESETA: \\ «LAS MATILLAS» (ALCALÁ DE HENARES, \\ MADRID) AS A CASE STUDY
}

\author{
PEDRO DÍAZ-DEL-RÍO (*) \\ SUSANA CONSUEGRA $(* *)$ \\ LEONOR PEÑA CHOCARRO $(* * *)$ \\ BELÉN MÁRQUEZ (****) \\ CRISTINA SAMPEDRO $(* * * * *)$ \\ RUTH MORENO (******) \\ DANIELE ALBERTINI (******) \\ BEATRIZ PINO (******)
}

\section{RESUMEN}

Presentamos los resultados de un proyecto interdisciplinar diseñado para las condiciones efímeras de una intervención de urgencia. La excavación de una formación arqueológica característica de la Prehistoria reciente de la Meseta peninsular, el yacimiento de 'fondos de cabaña', ha permitido, mediante la aplicación de una rigurosa metodología estratigráfica, una recuperación sistemática de los restos y el cruce de distintas evidencias cuantificadas (cerámica, industria lítica, semillas, huesos), proponer la existencia de una estructuración funcional y social del yacimiento, identificando lo que entendemos como un área

\footnotetext{
(*) Conde de la Cimera 4. Madrid 28040

(**) Trabajos de Arqueología y Restauración S.L. Reina 15, 3. Madrid 28004

$(* * *)$ Laboratorio de Arqueozoología (Arqueobotánica). Departamento de Biología, Facultad de Ciencias. Universidad Autónoma de Madrid. Cantoblanco. Madrid 28049

(****) Departamento de Paleobiología. Museo Nacional de Ciencias Naturales. José Gutiérrez Abascal, 2. Madrid 28006 (*****) Laboratorio de Arqueozoología (Paleoantropología). Departamento de Biología, Facultad de Ciencias. Universidad Autónoma de Madrid. Cantoblanco. Madrid 28049

$(* * * * *)$ Laboratorio de Arqueozoología (Arqueozoología). Departamento de Biología, Facultad de Ciencias. Universidad Autónoma de Madrid. Cantoblanco. Madrid 28049

El artículo fue remitido en su versión final el 5-VIII-97.
}

dedicada a la producción y reproducción del ciclo agrario. Todo ello posibilita la discusión de los factores sociales y económicos que determinan la formación de los depósitos arqueológicos y su distribución temporal y espacial, consecuencia de una sociedad cuyas relaciones de producción consideramos definidas por la apropiación de la tierra.

\begin{abstract}
The present paper deals with results obtained by an interdisciplinary project, conceived for the rescue excavation of a site in which pits are the unique features. Such sites comprise one of the ubiquitous archaeological formations of the later prehistory of the central Spanish Meseta. A stratigraphical recording system, systematic recovery of finds and the intersection of quantified evidence lead to the interpretation of a functional and social structure of the site, identifying what we understand as an agrarian production and reproduction area. Discussion is centred on social and economic factors involved in the formation of archaeological deposits and their spatial and temporal distribution, which are the result of a society in
\end{abstract}


which the relations of production are defined by the appropiation of land.

Palabras clave: Meseta peninsular. Madrid. Calcolítico. Edad del Bronce. Arqueología de urgencia. Registro estratigráfico. Flotación sistemática. Análisis traceológico. Análisis faunístico. Análisis antropológico. Análisis paleobotánico. Silos subterráneos. Paisaje agrario.

Key words: Iberian Meseta. Madrid. Copper Age. Bronze Age. Rescue archaeology. Stratigraphical record. Systematic flotation. Use-wear analysis. Faunal analysis. Human remain analysis. Archaeobotanical analysis. Storage pits. Agrarian landscape.

\section{INTRODUCCIÓN}

Una de las formaciones arqueológicas mas recurrentes a lo largo de la Prehistoria de la Península Ibérica, y en particular de la Meseta, es el yacimiento de 'fondos de cabaña'. Se caracteriza por la presencia de diversos tipos de fosas no correlacionadas estratigráficamente, lo que erróneamente se denomina 'estratigrafía horizontal' (1). La investigación ha relegado, si no olvidado, tanto la interpretación estratigráfica en sí como de la distribución de los residuos, en beneficio de un análisis morfotipológico cuya supuesta finalidad única es el establecimiento de fases. En pocas ocasiones se ha recurrido a evaluar cuantitativamente la información (p.e. Martínez Navarrete y Méndez, 1983), lo que en último término ha determinado una lectura homogeneizadora del registro: las estructuras se distribuirían de forma caótica existiendo una escasa variabilidad entre los depósitos. En consecuencia, la estrategia de excavación se reduce a vaciar las estructuras a fin de recuperar aquellos artefactos que permiten establecer su cronología.

Frente a esta tendencia, un programa de investigación que tenga como objeto prioritario de análisis el carácter pluriactivo de la economía agraria prehistórica (Díaz-del-Río, 1995) incidirá en la diversidad, buscando aquellas variables que permitan interpretar funcional y socioeconómicamente los procesos productivos. Desarrollar esta pro-

(1) En estos yacimientos existen relaciones de superposición entre los estratos, al menos dentro de las fosas, y por tanto son yacimientos estratificados. «La estratigrafía horizontal no es más que otro nombre incorrecto que se atribuye a una práctica normalmente utilizada en el análisis artefactual: no es un método estratigráfico» (Harris, 1991: 176). puesta, eminentemente paleoeconómica, requiere un enfoque interdisciplinar que aúne los esfuerzos de diversos especialistas (arqueozoología, arqueobotánica, paleoantropología, traceología, arqueometalurgia), una técnica de excavación estratigráfica (Spence, 1992) y un método sistemático de recuperación y cuantificación de los restos.

Dicho programa se puso en práctica en una excavación de urgencia enmarcada en el modelo de gestión arqueológica de la Comunidad de Madrid. Éste se caracteriza por la declaración de amplias zonas de protección cuyos límites exceden aquellos espacios con una máxima concentración de restos superficiales (Velasco, 1992). La exigencia administrativa de intervenir ante cualquier remoción de tierras en estas áreas de protección, ha permitido valorar uno de los aspectos potencialmente más beneficiosos del modelo: el estudio de áreas periféricas generalmente no documentadas en intervenciones sistemáticas, en las que suele primar el espacio nuclear.

\section{ANTECEDENTES Y METODOLOGÍA}

El yacimiento de 'Las Matillas' se dispone en la primera terraza del río Henares, a escasos $200 \mathrm{~m}$. del contacto con las llanuras de inundación del Henares y su afluente, el arroyo Camarmilla, en un terreno de elevada potencialidad agraria (4.480.9/ 466.8, Servicio Cartográfico Regional, Comunidad de Madrid, 1:25.000, hoja 560-I).

$\mathrm{Su}$ descubrimiento es resultado de la expansión urbana, documentándose con anterioridad a nuestra intervención un total de 54 'fondos de cabaña' en los $2.000 \mathrm{~m}^{2}$ del área A, excavados por el Taller Escuela de Arqueología y Rehabilitación de Alcalá de Henares, y al menos 8 en la B (Vega, 1996: 143). Ambos informes indicaban que el yacimiento se extendía tanto al norte como al sur de los espacios intervenidos, con una superficie superior a las dos hectáreas.

Los materiales recuperados no fueron estudiados en profundidad, por lo que la supuesta ausencia de formas cerámicas decoradas y la relativa abundancia de industria lítica llevó a encuadrar el yacimiento en una fase calcolítica no campaniforme. Nuestra revisión de 18.166 fragmentos cerámicos y 1.918 líticos del área $\mathrm{A}$ indican varias agrupaciones morfotipológicas desigualmente representadas: Calcolítico, una fase indeterminada de la Edad del Bronce y Bronce Final. 

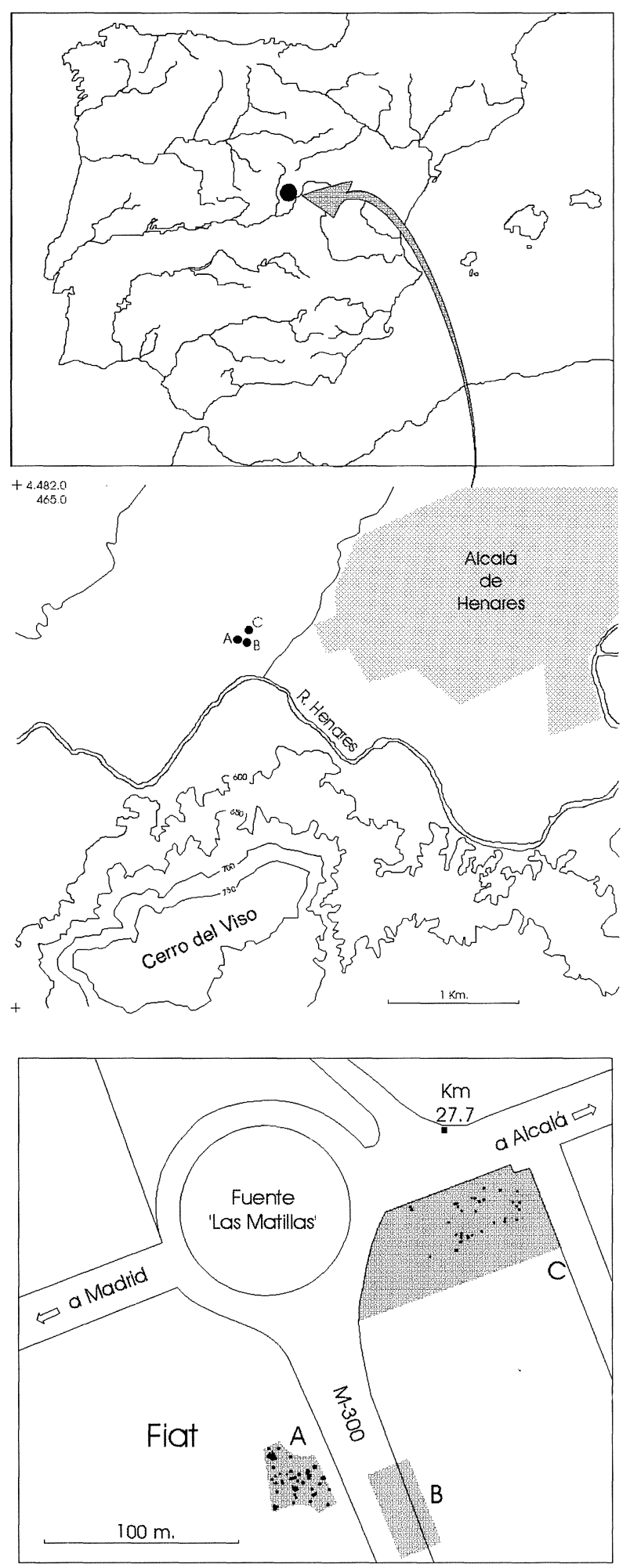

Fig. 1. Localización de las áreas del yacimiento de 'Las Matillas' (Alcalá de Henares, Madrid) citadas en texto.
El potencial arqueológico de los $11.575 \mathrm{~m}^{2} \mathrm{del}$ área C se evaluó a partir de 20 zanjas de 10 x 1'5 m. y $20 \mathrm{~m}$ de equidistancia (2). La presencia de un 'fondo', situado en el extremo opuesto a las áreas A y B y sin evidencia alguna de estratificación entre el manto vegetal y el sedimento geológico, permitió recurrir a una máquina motoniveladora que retiró gran parte del manto vegetal. La posterior limpieza manual de $4.250 \mathrm{~m}^{2}$ llevó a delimitar en superficie 34 estructuras prehistóricas así como un conjunto de fosas y zanjas de riego contemporáneas (3).

Nuestra excavación se realizó siguiendo el método estratigráfico propuesto por Harris (1991), renunciando a la extracción de niveles artificiales. Todas aquellas superficies resultantes de la excavación de sedimentos preexistentes, fuesen antrópicos o geológicos, se denominaron 'elementos interfaciales verticales' o 'interfaces', y 'depósitos' a los diversos estratos que rellenan cada interfaz (4) (Harris,' 1991; Spence, 1992). Esta terminología evita cualquier discusión sobre aspectos funcionales o semánticos (basurero, fondo de cabaña, hoya...), estableciendo una clara distinción entre dos acciones pretéritas: la excavación de estructuras y su posterior relleno o modificación.

Las 34 interfaces prehistóricas detectadas tras la limpieza superficial fueron identificadas mediante un número de unidad estratigráfica (centenas: u.e. $100,200 \ldots)$, concediendo un número correlativo a cada unidad incluida en su interior (por ejemplo: u.e. $101,102,103 \ldots$... . El sedimento extraído, individualizado por u.e., fue introducido en sacos de 50 1. para su posterior tratamiento en una máquina de flotación conectada a la toma general de la parcela. Excepto en el caso de los depósitos de la u.e. 100, la media procesada fue de 201. por unidad. Las mallas utilizadas, $1 \mathrm{~mm}$. de luz en el interior y $250 \mu$ en el exterior del bidón, permitieron la recuperación de restos de muy pequeño tamaño en un total de 112 muestras (2.663 1.), todas ellas depósitos de 32 de las 34 interfaces prehistóricas documentadas.

(2) Tras valorar el solar mediante las zanjas, la propiedad vendió parte de la parcela. Denominamos 'área C' a los $4250 \mathrm{~m}^{2}$ excavados por nosotros.

(3) La inversión de trabajo en la limpieza manual total no es frecuente en este tipo de intervenciones. Dado que muchas de las estructuras contaban con rellenos muy similares al terreno geológico, habría resultado imposible detectarlas.

(4) En adelante, cuando nos refiramos al conjunto de restos recuperados en la totalidad de los depósitos de relleno de una interfaz, utilizaremos el número de identificación de la misma. Evidentemente, una interfaz es una superficie que carece de material arqueológico. 


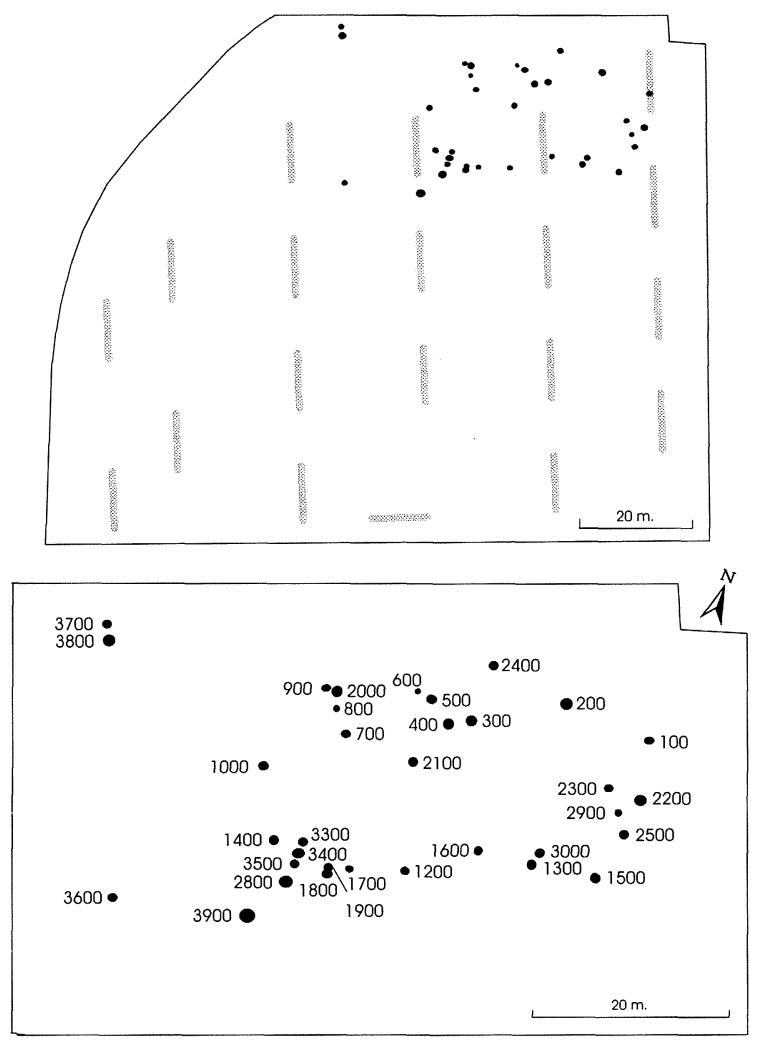

Fig. 2. Distribución de las zanjas de sondeo en el Area C de 'Las Matillas' (Alcalá de Henares, Madrid) e identificación de las interfaces prehistóricas.

Como resultado, se ha obtenido el primer conjunto botánico de la Prehistoria reciente madrileña procedente de un muestreo sistemático, recuperando gran parte de los restos faunísticos, cerámicos y líticos de menor tamaño del yacimiento.

\section{REGISTRO ARQUEOLÓGICO}

\section{a. Interfaces y depósitos}

Tenemos constancia de la inexistencia de restos tanto al norte como al este del área C. En cuanto al sur, los más próximos se encuentran a no menos de $40 \mathrm{~m}$. Todas las interfaces se distribuyen en el área excavada de forma aparentemente caótica y, a excepción de tres, se encuadran dentro de la mitad oriental del solar, dejando amplios espacios intermedios en la mayor parte de los casos.

El cálculo en litros de la capacidad de cada interfaz permite agruparlas en dos conjuntos: inferiores a los 610 l. y superiores a los 1.150 l. Esta clasificación recurre a una escala «proporcional», frente a la «nominal» (Shennan, 1992: 25) generalmente utilizada por otros autores (p.e. Valiente, 1987: 132) la cual hace depender las agrupaciones de características exclusivamente morfológicas, en gran medida subjetivas (5).

Cada agrupación tiene una aparente homogeneidad morfológica, en especial las de menor capacidad, en las que la interfaz es lisa. Frente a ello, una buena parte de las estructuras mayores presentan interfaces alteradas, indicativo del tiempo en que permanecieron sin cerramiento superior, vacías total o parcialmente (6). En algún caso se han documentado extracciones intencionadas de sedimento de las paredes, generalmente asociadas a inhumăciones: en la u.e. 100 se vació una covacha lateral para depositar un individuo en posición fetal (u.e. 109), mientras que en la u.e. 1300 se extrajo sedimento de la pared para formar con él un estrato sobre el cual depositar a otro (u.e. 1304).

En cuanto a su distribución espacial, las interfa'ces de mayor capacidad se agrupan en los límites norte, sur y este. Como no todas ellas pueden ser adscritas al mismo momento cronotipológico parece que, al margen del 'factor tiempo', la distribución conserva como característica su excavación exclusiva en determinados espacios.

Los depósitos presentan una alta homogeneidad sedimentológica. La mayor parte han sido diferenciadas por ligeros matices de coloración o textura y la presencia/ausencia de inclusiones (caliches, carboncillos...). Unicamente pueden distinguirse tres tipos generales: arenas y arcillas naturales y depósitos sedimentarios alterados. La presencia de arenas limpias alternando en posiciones intermedias de las estratigrafías (por ejemplo depósitos de u.e. 1600) puede ser indicativa de la simultaneidad de algunas de las estructuras, pues muchas de ellas no profundizan lo suficiente para acceder a este estrato geológico. Esto exige admitir la contemporaneidad en la excavación de algunas y el relleno de otras. En cualquier caso, la colmatación temporal con arenas u

(5) La agrupación por capacidades permite analizar estadísticamente la variabilidad entre estructuras, y por tanto puede resultar indicativa a la hora de establecer regularidades en las mismas y entre los yacimientos. Por ejemplo, las capacidades del área $\mathrm{C}$ se asemejan en gran medida a las documentadas en Moncín (Borja, Zaragoza), en el que se han diferenciando dos grupos: los de aproximadamente 330 1. y los de 1300 l. (Harrison et alii, 1994: 83).

(6) Un análisis experimental del proceso de erosión en silos subterráneos expuestos a la intemperie puede verse en Reynolds (1974). Durante nuestra intervención observamos el alto grado de erosión provocado por la lluvia sobre estructuras ya excavadas. Por tanto, el lapso de tiempo no es necesariamente amplio, siendo la única condición que carezcan de protección en la boca.

T. P., 54, n. $^{\circ} 2,1997$ 

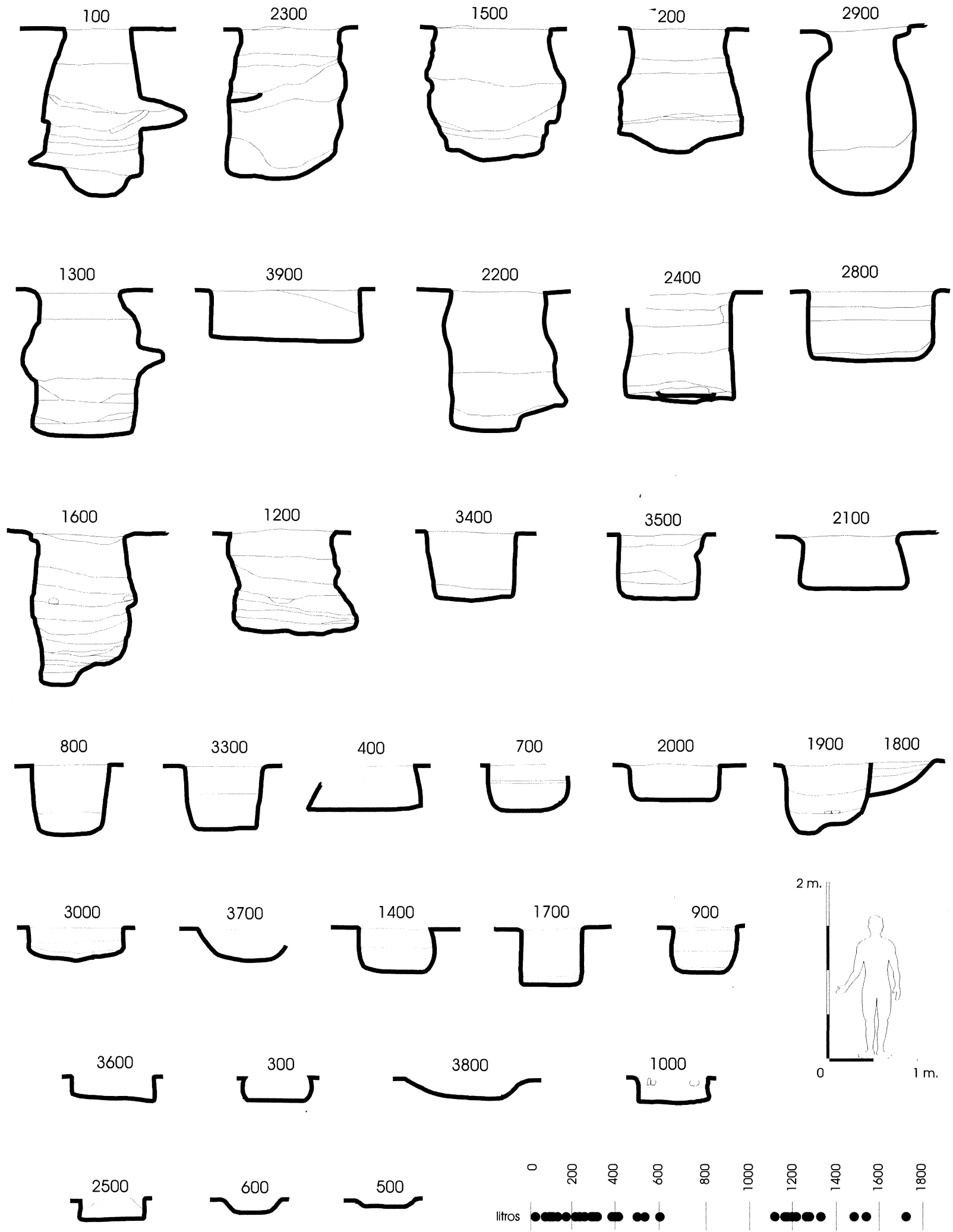

Fig. 3. Secciones acumulativas de las estructuras documentadas en el Area C. 


\begin{tabular}{|c|c|c|c|c|c|c|c|c|c|c|c|c|c|c|c|}
\hline \multirow[t]{2}{*}{ Interfaz } & \multirow{2}{*}{$\begin{array}{l}\text { Capac. } \\
\text { (litros) }\end{array}$} & \multirow{2}{*}{$\begin{array}{l}\text { U.e. } \\
\text { relleno }\end{array}$} & \multicolumn{4}{|c|}{ Cerámica } & \multicolumn{3}{|c|}{ Industria lítica } & \multicolumn{2}{|c|}{ NR Botánicos } & \multirow[t]{2}{*}{ Inh. } & \multirow{2}{*}{$\begin{array}{l}\text { Ind. } \\
\text { ósea }\end{array}$} & \multirow{2}{*}{$\begin{array}{c}\mathrm{NR} \\
\text { fauna }\end{array}$} & \multirow[t]{2}{*}{ Atrib. } \\
\hline & & & NR & Sel. & Dec. & Gr. & NR & las. & lám. & Silv. & Cereal & & & & \\
\hline 100 & 1390 & 11 & 100 & 2 & - & 389 & 71 & 20 & 8 & 1629 & 14 & 2 & - & 49 & B. \\
\hline 200 & 1510 & 6 & 140 & 8 & - & 350 & 23 & 7 & 5 & 1 & - & - & - & - & B. \\
\hline 300 & 130 & 1 & 4 & - & - & 10 & 2 & - & - & - & - & - & - & - & $?$ \\
\hline 400 & 390 & 1 & - & - & - & - & 1 & - & - & - & - & - & - & - & $?$ \\
\hline 500 & 20 & 1 & 15 & - & - & 30 & 2 & 1 & - & - & - & - & - & 1 & $?$ \\
\hline 600 & 30 & 1 & 77 & 13 & - & 593 & 4 & 1 & 2 & - & - & - & - & & C. \\
\hline 700 & 330 & 3 & 69 & 2 & - & 1120 & 6 & 1 & 1 & 5 & 1 & - & - & 48 & C. \\
\hline 800 & 420 & 2 & 13 & 1 & - & 41 & 9 & 6 & - & 5 & 57 & - & - & 47 & C. \\
\hline 900 & 190 & 4 & 4 & - & - & 1 & 3 & - & 1 & 1 & - & - & - & 14 & $?$ \\
\hline 1000 & 110 & 5 & 24 & 2 & 1 & 191 & 15 & 4 & - & 2 & - & - & - & 16 & B. \\
\hline 1200 & 1150 & 9 & 72 & 10 & - & 425 & 14 & 3 & - & 10 & 1 & - & - & 18 & B. \\
\hline 1300 & 1300 & 8 & 71 & 7 & 1 & 191 & 52 & 13 & 8 & 5 & 2 & 1 & - & 114 & B. \\
\hline 1400 & 250 & 3 & 28 & - & - & 118 & 19 & 3 & 4 & 2 & - & - & - & 303 & $?$ \\
\hline 1500 & 1570 & 6 & 205 & 20 & 1 & 741 & 64 & 18 & 16 & - & - & - & - & 11 & B. \\
\hline 1600 & 1200 & 18 & 48 & 8 & - & 669 & 18 & 4 & 3 & 1 & - & - & - & - & B. \\
\hline 1700 & 230 & 2 & 142 & 14 & 4 & 1367 & 10 & 4 & 1 & - & - & - & - & 46 & B. \\
\hline 1800 & 270 & 3 & 51 & 4 & - & 275 & 3 & 2 & - & - & - & - & - & 22 & C. \\
\hline 1900 & 310 & 3 & 30 & 3 & - & 418 & - & - & - & 2 & - & - & - & 134 & C. \\
\hline 2000 & 310 & 1 & 23 & 1 & - & 71 & - & - & - & - & - & - & - & 21 & B. \\
\hline 2100 & 510 & 1 & 14 & - & - & 160 & 2 & - & - & - & - & - & - & - & $?$ \\
\hline 2200 & 1240 & 3 & 90 & 10 & 1 & 425 & 22 & 4 & 4 & 12 & - & - & - & 2 & B. \\
\hline 2300 & 1750 & 8 & 37 & 8 & - & 633 & 21 & 8 & 2 & 1 & - & 2 & - & 104 & B. \\
\hline 2400 & 1220 & 8 & 274 & 20 & 4 & 1220 & 31 & 5 & 3 & 1 & - & - & - & 17 & B. \\
\hline 2500 & 90 & 2 & 1 & - & - & 7 & 42 & 20 & 5 & - & - & - & - & - & $?$ \\
\hline 2800 & 1200 & 4 & 81 & 6 & - & 535 & 48 & 13 & 10 & - & - & - & 2 & 514 & C. \\
\hline 2900 & 1300 & 2 & 14 & - & - & 96 & 10 & 4 & - & 1 & - & - & - & - & $?$ \\
\hline 3000 & 300 & 3 & 20 & - & - & 91 & 22 & 5 & 4 & - & - & - & - & 74 & $?$ \\
\hline 3300 & 410 & 3 & 3 & 2 & - & 81 & 3 & - & 2 & 5 & - & - & - & 20 & C. \\
\hline 3400 & 610 & 2 & 42 & 1 & - & 310 & 5 & 1 & 1 & 30 & - & - & - & 92 & C. \\
\hline 3500 & 540 & 4 & 27 & 2 & 1 & 466 & - & - & - & - & - & - & - & 139 & B. \\
\hline 3600 & 150 & 1 & 14 & - & - & 15 & 8 & 2 & 1 & - & - & - & - & 2 & $?$ \\
\hline 3700 & 250 & 1 & 9 & - & - & 36 & - & - & - & - & - & - & - & - & $?$ \\
\hline 3800 & 110 & 1 & 9 & - & - & 15 & 1 & - & - & - & - & - & - & - & $?$ \\
\hline 3900 & 1290 & 2 & 11 & 1 & - & 100 & 22 & 10 & 3 & - & - & - & - & 1 & C. \\
\hline
\end{tabular}

Tab. 1. Cuantificación del registro arqueológico y hallazgos del Area C de 'Las Matillas' (Alcalá de Henares, Madrid). ' $\mathrm{B}$ ' = Bronce, ' $\mathrm{C}$ ' = Calcolítico.

T. P., 54, n. $^{\circ} 2,1997$ 
otros sedimentos es frecuente en grupos que utilizan el almacenaje subterráneo, rellenando los silos de sedimentos fácilmente extraíbles con la finalidad de conservar intactas sus paredes entre ciclos agrarios (Villes, 1981).

La totalidad de los depósitos se distinguen de los documentados en otros yacimientos (p.e. Martínez Navarrete y Méndez, 1983; Valiente, 1987; 1992; Priego y Quero, 1992), generalmente con altas densidades de materia orgánica y abundantes estratos 'cenicientos'.

En conclusión, las evidencias estratigráficas muestran una distribución perimetral de las estructuras de mayor capacidad y una ausencia de elementos sedimentológicos que permitan suponer actividad alguna de transformación doméstica (hogares, actividades artesanales...). Ello contrasta, por su proximidad, con las 54 del área A: dos estructuras de más de $5 \mathrm{~m}$. de diámetro, presencia de depósitos 'cenicientos', alta densidad de estructuras y abundancia de restos recuperados.

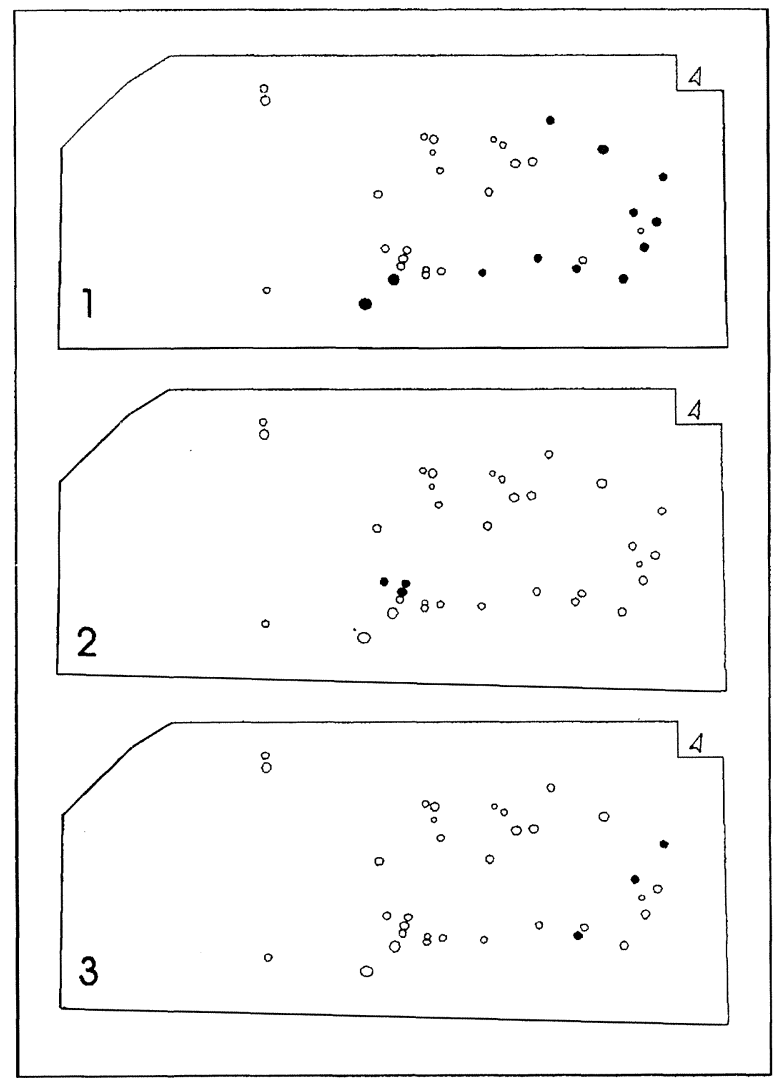

Fig. 4. 'Las Matillas' (Alcalá de Henares, Madrid), Area C: 1. Distribución de las intefaces de mayor capacidad. 2. Localización de los cráneos animales aislados. 3. Localización de las inhumaciones.

\section{b. Cerámica}

Se recuperaron un total de 1.762 fragmentos de cerámica a mano, de los cuales $145(8$ '2\%) permiten identificar su forma o presentan decoración. La variabilidad en su frecuencia de aparición dentro del yacimiento es elevada: 18.166 en las 49 estructuras detectadas en el área A frente a los 1.762 en las 34 del área C. El bajo porcentaje de cerámicas selectas y su alto índice de fragmentación (76'8\% $<3$ cm., 16'2\% 3-5 cm., 5'3\% 5-8 cm., 1'6\% > 8 $\mathrm{cm}$.) limitan la adscripción cronotipológica de la segunda. Doce estructuras $\left(35^{\prime} 2 \%\right)$ carecen de fragmentos selectos y $16(47 \%)$ cuentan con menos de 10. El caso de los depósitos de la u.e. 100, con sólo dos fragmentos de borde no decorados menores de $3 \mathrm{~cm}$, dificulta la adscripción cronológica de las inhumaciones.

La tabla tipológica del área $\mathrm{C}$ permite distinguir cinco grupos según su perfil: en $\mathrm{S}$, cerrados de perfil simple, abiértos de perfil simple, rectos y carenados. La decoración más representada es la impresión en el labio (0'7\% del total, 8'9\% del total selecto, $11 \%$ del total de bordes) (7), seguida de la pintura (roja o negra), tanto exterior como interior, detectada en 5 fragmentos.

Los indicadores tipológicos a los que se puede recurrir para descartar la pertenencia de los conjuntos, estratigráficamente aislados, a una fase calcolítica tipo 'Esgaravita' (Martínez Navarrete, 1979; 1987; Díaz-del-Río y Sánchez, 1988) son exclusivamente tres: bordes decorados, vasos de perfil en $\mathrm{S}$ y carenas medias. Estos indicadores son individualmente poco efectivos aunque, en conjunto, servirían como 'discriminadores' cronológicos: los bordes impresos se encuentran mayoritariamente en fases de la Edad del Bronce (p.e. Valiente, 1987; 1992), las carenas medias han sido tradicionalmente consideradas posteriores al Calcolítico aunque se encuentran representadas en yacimientos con campaniforme como 'El Ventorro' (Priego y Quero, 1992: 217-221) y, por último, los perfiles en $S$ parecen estar presentes en yacimientos calcolíticos como 'La Loma de Chiclana' (Díaz-Andreu et alii, 1992) o 'El Ventorro' (Priego

(7) La presencia de bordes impresos es una de las características tipológicas utilizadas para incluir el conjunto dentro del Bronce 'Clásico' madrileño (Blasco, 1987a). Hasta la actualidad no existe ninguna excavación publicada que permita establecer su representatividad. En el caso de 'La Loma del Lomo' los porcentajes de bordes impresos sobre un total de 24227 fragmentos son: 0'1\% sobre el total, 1 ' $2 \%$ sobre total de selecto, 1' $6 \%$ sobre total de bordes (elaboración propia a partir de Valiente, 1992). 


\begin{tabular}{|c|c|c|c|c|c|c|c|c|}
\hline \multirow{2}{*}{$\begin{array}{l}\overline{0} \\
\overline{0} \\
\overline{0} \\
\underline{1}\end{array}$} & \multicolumn{4}{|c|}{ Cerámica } & \multicolumn{3}{|c|}{ Industria lítica } & \multirow{2}{*}{$\begin{array}{l}\text { Ind. } \\
\text { ósec }\end{array}$} \\
\hline & NR & Sel. & :Dece & Gr. & NR & las. & lám. & \\
\hline 1 & 4713 & 520 & 7 & 73100 & 451 & 157 & 78 & 11 \\
\hline 2 & 1534 & 169 & 4 & 28040 & 125 & 36 & 14 & 2 \\
\hline 3 & 52 & 6 & - & 630 & 7 & 4 & - & - \\
\hline 5 & 1010 & 159 & 2 & 23300 & 88 & 30 & 9 & 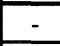 \\
\hline 6 & 228 & 25 & 4 & 2710 & 83 & 34 & 16 & 1 \\
\hline 7 & 28 & 5 & - & 255 & 7 & 2 & - & - \\
\hline 8 & 17 & 7 & - & 300 & 4 & - & 7 & \\
\hline 9 & 19 & 1 & - & 245 & 1 & 1 & - & - \\
\hline 10 & 408 & 31 & 3 & 3280 & 68 & 19 & 16 & - \\
\hline 11 & 270 & 21 & - & 3715 & 91 & 36 & 9 & - \\
\hline 12 & 197 & 31 & - & 3030 & 34 & 11 & 6 & - \\
\hline 16 & 552 & 72 & - & 9900 & 21 & 9 & 3 & 1 \\
\hline 17 & 510 & 46 & 1 & 12275 & 73 & 27 & 12 & - \\
\hline 18 & 413 & 80 & 1 & 11000 & 19 & 11 & 1 & - \\
\hline 19 & 105 & 7 & - & 1555 & 1 & - & - & - \\
\hline 20 & 586 & 55 & - & 9145 & 122 & 45 & 15 & - \\
\hline 21 & 27 & - & - & 280 & 16 & 4 & 5 & 1 \\
\hline 22 & 7 & - & - & 40 & 3 & 1 & - & - \\
\hline 23 & 400 & 28 & - & 3290 & 66 & 23 & 8 & - \\
\hline 24 & 3 & - & - & 30 & 1 & 1 & - & - \\
\hline 25 & 136 & 11 & 2 & 970 & 36 & 11 & 5 & - \\
\hline 26 & 438 & 36 & 1 & 7880 & 20 & 6 & 1 & - \\
\hline 27 & 158 & 3 & - & 2075 & 33 & 9 & 4 & - \\
\hline 28 & 94 & 6 & - & 1310 & 38 & 18 & 3 & - \\
\hline 29 & 47 & 2 & - & 955 & 9 & 2 & 3 & - \\
\hline 30 & 6 & - & - & 30 & 1 & - & 1 & - \\
\hline 31 & 34 & 5 & - & 940 & 1 & - & - & - \\
\hline 32 & 2 & 1 & - & 30 & - & - & - & - \\
\hline 33 & 11 & 2 & - & 190 & - & - & - & - \\
\hline 34 & 12 & 2 & - & 95 & 3 & 1 & 1 & - \\
\hline 35 & 16 & 4 & - & 190 & 1 & 1 & - & - \\
\hline 36 & 635 & 99 & 1 & 12640 & 66 & 26 & 8 & 2 \\
\hline 38 & 141 & 18 & - & 2390 & 8 & 5 & 1 & - \\
\hline 40 & 122 & 8 & - & 2275 & 16 & 8 & 3 & - \\
\hline 41 & 26 & 1 & - & 575 & - & - & - & - \\
\hline 51 & 322 & 48 & - & 5800 & 19 & 6 & 2 & - \\
\hline 52 & 280 & 24 & - & 4901 & 15 & 9 & 1 & - \\
\hline 53 & 7 & 1 & - & 200 & 1 & - & - & - \\
\hline 34 & 121 & 14 & - & 3330 & 4 & - & - & - \\
\hline$a$ & 2144 & 293 & 2 & 41585 & 165 & 74 & 17 & 4 \\
\hline $\mathrm{b}$ & 468 & 86 & 1 & 11895 & 28 & 10 & 3 & - \\
\hline $\mathrm{C}$ & 573 & 78 & 1 & 11680 & 56 & 20 & 10 & 2 \\
\hline$d$ & 241 & 33 & - & 5690 & 25 & 14 & 5 & - \\
\hline$e$ & 116 & 86 & - & 11460 & 70 & 20 & 14 & - \\
\hline$f$ & 197 & 14 & - & 2775 & 19 & 8 & 3 & - \\
\hline$g$ & 36 & 5 & - & 450 & 3 & 2 & 1 & - \\
\hline $\mathrm{h}$ & 87 & 13 & - & 1770 & - & - & - & - \\
\hline$i$ & 17 & - & $\vdots-\vdots$ & 630 & - & - & - & - \\
\hline Total & 18166 & 2156 & 30 & 320831 & 1918 & 701 & 281 & 24 \\
\hline
\end{tabular}

Tab. 2. Cuantificación del registro arqueológico disponible del Area A de 'Las Matillas' (Alcalá de Henares, Madrid).

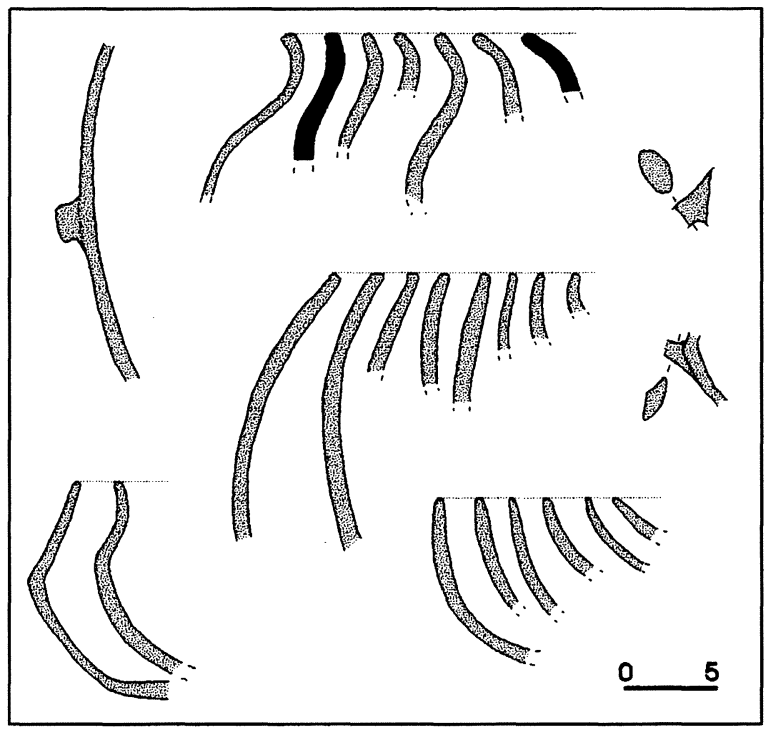

Fig. 5. Selección de perfiles cerámicos del Area $\mathrm{C}$ de 'Las Matillas' (Alcalá de Henares, Madrid). En negro fragmentos de borde impreso.

y Quero, 1992: 223) aunque aparentemente se generalizan en momentos posteriores (8).

Atendiendo a los conjuntos, 13 (38'2\%) estructuras sin cerámica selecta quedarían sin clasificar; diez (29'4\%) se incluirían en el denominado Bronce Clásico (Blasco, 1987a: 90-95) por contar con bordes impresos (7) y/o carenas medias (3), quedando adscritos al conjunto 'Esgaravita' únicamente 11 estructuras (32'3\%). Evidentemente, esta adscripción debe tomarse con cautela, pues 8 de ellas cuentan con menos de 5 fragmentos selectos.

La dificultad para clasificar individualmente las estructuras del área $\mathrm{C}$ dentro de un conjunto tipológico específico (Calcolítico o Bronce 'Clásico') resulta de compartir gran parte de las formas simples derivadas de la esfera. El escaso volumen de cerámicas, y no tanto su cronología anterior, podría ser el responsable de la ausencia de formas características del Bronce 'Clásico'. Todo ello es un ejemplo extremo de las consecuencias generadas por una periodización de la Prehistoria Reciente basada en aspectos morfotipológicos mino-

(8) A pesar de las abundantes intervenciones en yacimientos de la Prehistoria reciente en la Meseta, existe un serio problema de trasmisión de información, siendo escasas las publicaciones que presentan los conjuntos cerámicos mínimamente sistematizados. Esta clasificación es indicativa teniendo en cuenta el estado actual de conocimiento. 
ritarios en los yacimientos (9). En definitiva, su aplicación exige admitir la presencia de dos conjuntos en el área, Calcolítico y Bronce 'Clásico'.

\section{c. Industria lítica}

Se recuperaron 553 piezas, repartidas en los depósitos de 30 interfaces. Las materias primas representadas son el sílex $(71 \%)$, la cuarcita $\left(14^{\prime} 6 \%\right)$ y el cuarzo (13'3\%). El conjunto ha sido dividido en seis categorías: núcleos, lascas, industria laminar, fragmentos (10), restos de talla o debris y piezas retocadas. Los dos grupos mas representados son los fragmentos (32'7\%) y lascas ( $\left.28^{\prime} 5 \%\right)$, seguidos de la industria laminar $(15,7 \%)$ y restos de talla (13'3\%). Las piezas retocadas ascienden a 46 $\left(8^{\prime} 3 \%\right)$ que incluyen un repertorio de 26 útiles: muescas (8), denticulados (6), perforadores (4), raspadores (2) y otros ( 1 geométrico, 2 truncaturas, 2 microburiles, 1 foliáceo). En general predomina el retoque simple y marginal sobre lascas y fragmentos.

Son cinco los núcleos recuperados: uno poliédrico para extracción de laminitas, y cuatro para lascas (1 bipolar, 1 multipolar, 2 indeterminados). En cuanto a la industria laminar, y aunque la fragmentación no permite estimar la relación longitud/ anchura, predominan las piezas con anchura comprendida entre $11-20 \mathrm{~mm}$. (50\% del total) y 0-10 $\mathrm{mm}$. (46'6\%), mientras que el intervalo $>20 \mathrm{~mm}$. está representado por una sola pieza.

Al contrario de lo observado para los restos cerámicos, destaca la relación entre la capacidad de las interfaces y el número de restos que contienen. En todas las estructuras domina la talla no laminar, aunque está por completo ausente en los depósitos de 8 de las interfaces. Los escasos 'útiles' se reparten de forma homogénea entre los depósitos de 9 interfaces, a excepción de los de la u.e. 1500, en los cuales se recuperaron un total de 11. Conviene señalar la presencia de toda la cadena operativa en el conjunto, aunque precisando la escasa representatividad de los 'útiles' en ella.

Dada la difícil clasificación cronotipológica de la cerámica, la proporción de los tipos de soporte

(9) El problema anotado es frecuente en gran parte de los yacimientos de la Meseta, aunque en escasas ocasiones se hace explícito. Una excepción es 'El Espinillo' (Villaverde, Madrid), en el que se excavaron un total de 98 'fondos', de los cuales 42 $\left(422^{\prime} 8 \%\right)$ quedaron sin adscripción cronológica «debido a la escasez o ausencia de materiales significativos» (Baquedano y Blanco, 1994: 16).

(10) Agrupa aquellos fragmentos de talla indeterminados que no pueden ser asignados a ninguna otra categoría. en el conjunto podría facilitar la atribución cronológica de las distintas interfaces. Sin embargo, el índice laminar de ambos conjuntos de estructuras (calcolíticas y Bronce Clásico) es prácticamente idéntico: 35 ' $8 \%$ y 35 '9\% respectivamente. Esta circunstancia difiere claramente de la señalada para otros yacimientos. En la Loma de Chiclana (Díaz-Andreu et alii, 1992: 67-68) la industria sobre lasca representa el 66'5\% del total, reduciéndose al 8'92\% la laminar. En el caso contrario, la industria de la Loma del Lomo se realiza «fundamentalmente sobre láminas o microláminas» (Valiente, 1992: 293). El problema radica, por tanto, en conceder un valor cronológico al índice laminar. La presencia masiva de fragmentos y restos de talla (47' $1 \%$ del total) en el área $C$ induce a atribuir sus valores a la metodología de recuperación sistemática, no empleada en ninguno de los yacimientos publicados del área.

Hemos cómpletado el análisis tipológico con otro traceológico, generalmente ausente de la investigación en la Meseta. Este tipo de análisis es complejo en contextos de economías productoras, requiriendo la elaboración de un programa experimental adecuado. Con la finalidad de determinar la viabilidad de un futuro estudio funcional total, seleccionamos 249 piezas, que constituyen el registro completo de 10 de las estructuras (u.e. 100, $1300,2300,3000,3300,3400,3500,3600,3800$ y 3900 ), eliminando del estudio núcleos, fragmentos informes, debris, piezas quemadas y aquellas con pátinas blancas muy desarrolladas (11).

En la mayor parte de los casos, las múltiples alteraciones de las piezas han imposibilitado la detección de huellas de uso. Las principales identificadas han sido el pulimento de tierra, pátinas ('lustre de suelo' y pátinas blancas sobre toda la superficie), rodamiento, gelifracción, modificaciones por fuego (14'4\% de las piezas analizadas), bright spots y concreciones. En una valoración global, cabe destacar que procesos como la gelifracción también parecen haber afectado a algunos

(11) Todas las piezas de sílex han sido lavadas en cubeta de ultrasonidos con agua y detergente amoniacal. Las que presentan restos de concreciones han sido tratadas con una disolución de ácido clorhídrico (CLH) al 50\% durante $10 \mathrm{~min}$., hidróxido de potasio $(\mathrm{KOH})$ en la misma proporción y tiempo y por último un baño de agua destilada durante otros $10 \mathrm{~min}$. (entre baños, las piezas se aclararon con agua). Para eliminar la grasa procedente de la manipulación, las piezas se sumergen en acetona y alcohol. La observación se ha realizado con un microscopio metalográfico de luz incidente y reflejada, con un rango de aumentos de 50 a $500 x$. En dos casos se ha requerido el uso del Microscopio Electrónico de Barrido. 
restos de fauna (12), mientras que la conservación diferencial de las piezas en función de las estructuras es relevante tanto en el caso de las concreciones como de las pátinas blancas: en algunas estructuras ninguna pieza presentaba concreción (en especial u.e. 3001) frente a otras en las que este tipo de alteración era mayoritaria.

Dos fragmentos de sílex con huellas de uso proceden de los depósitos de la u.e. 1300. El primero, con filo transversal recto relativamente abrupto muy embotado, cuenta en su cara dorsal con una gran concentración de desconchados cuya morfología rectangular y disposición superpuesta puede atribuirse a una posible acción transversal aplicada sobre materia dura (13). En el segundo, con dos muescas proximales y una fractura distal, se ha detectado sobre su cara dorsal una banda brillante, posiblemente una almáciga de sujeción, que lo divide en dos mitades. La recubierta por el mango aparece fresca y la otra patinada. De no haber mediado un estudio traceológico, ambas piezas habrían sido catalogadas como 'restos de talla', lo que relativiza cualquier generalización respecto a la ausencia o escasa presencia de útiles tipológicamente clasificables en momentos avanzados de la Prehistoria reciente.

En cuanto a los útiles pulimentados, se han recuperado dos hachas de fibrolita (u.e. 3503 y 3801). La primera, un fragmento distal de pequeño tamaño sin evidencias de uso, mientras que en la segunda se observa una gran destrucción del filo y una serie de desconchados superpuestos de gran tamaño, propios de actividades de percusión. Los desconchados se concentran en una de las caras, lo que lleva a pensar en la existencia de un ángulo de trabajo oblicuo.

Dos alisadores (u.e. 1205 y 2801), una moledera (u.e. 1504) y dos manos de moler (u.e. 101 y 1005) completan el repertorio de utillaje en piedra.

\section{d. Fauna}

La fauna del yacimiento incluye tanto restos de moluscos como de anfibios, reptiles y mamíferos.

(12) Los efectos de este proceso se evidencian, por ejemplo, en el tipo de fracturación de los dientes de bóvido.

(13) La utilidad de los desconchados como indicadores de uso es desigualmente valorada. Mientras algunos (Tringham et alii, 1974: 192) consideran que no es difícil distinguirlos de los producidos por causas naturales dada su disposición relativamente regular, otros opinan que algunos factores naturales pueden producirla (Vaughan, 1985).

\begin{tabular}{|c|c|c|c|c|c|}
\hline \multicolumn{2}{|l|}{ TAXONES } & \multirow{2}{*}{$\frac{N R}{78}$} & \multirow{2}{*}{$\frac{\% \text { NR }}{4^{\prime} 3}$} & \multirow{2}{*}{$\frac{\mathrm{NMI}}{11}$} & \multirow{2}{*}{$\frac{\% \mathrm{NMI}}{25}$} \\
\hline Bos taurus & Vaca & & & & \\
\hline Ovis aries & Oveja & 3 & $0^{\prime} 2$ & 3 & $66^{\prime} 8$ \\
\hline OvisıCapra & Ovicaprino & 91 & 5 & 17 & $38 ' 6$ \\
\hline Sus $s p$. & Suido & 3 & $0^{\prime} 2$ & 3 & $6 ' 8$ \\
\hline Sus domesticus & Cerdo & 18 & 1 & 3 & $6 ' 8$ \\
\hline Canis familiaris & Perro & 6 & $0^{\prime} 3$ & 2 & $4^{\prime} 6$ \\
\hline Carnivora & Carnivoro & 1 & $00^{\prime} 1$ & 1 & $2 ' 3$ \\
\hline Cervus elaphus & Ciervo & 26 & $1 ' 4$ & 4 & $9^{\prime} 1$ \\
\hline Macro S.I. & & 109 & 6 & - & - \\
\hline Meso S.I. & & 437 & $24 ' 2$ & - & - \\
\hline S.I. & & 1034 & $57 ' 3$ & - & - \\
\hline Total mamíferos & & 1806 & 100 & 44 & 100 \\
\hline Unionacea & eja de río & 3 & - & 2 & - \\
\hline Dentalium $s p . \mathrm{C}$ & nillo elefante & 1 & - & 1 & - \\
\hline TOTAL & & 1810 & - & 47 & - \\
\hline
\end{tabular}

Tab. 3. Distribución de abundancias de los taxones presentes en el Area C de 'Las Matillas' (Alcalá de Henares, Madrid). Número de restos (NR) y Número Mínimo de Individuos (NMI).

El análisis (14) se ha centrado en los macromamíferos y moluscos. El interés arqueozoológico de la muestra es obvio, dado que se trata de uno de los pocos yacimientos de la Prehistoria reciente de la Meseta Sur en el que se ha seguido una metodología rigurosa en la recuperación de los restos, lo que permite evaluar la representatividad de la muestra.

El estado de conservación de los restos óseos es pésimo, con un altísimo grado de fracturación y alteración superficial (costras calcáreas, disolución como resultado del ataque radicular, etc). Por ello el porcentaje de muestra identificada es muy bajo $\left(12{ }^{\prime} 6 \%\right)(15)$, siendo inabordable el estudio de procesos de carnicería o la estimación de la biomasa de los taxones. Dentro de los restos sin identificar destaca el alto número no asignable siquiera a las categorías de macro y mesomamífero (57'3\%). Sus minúsculas tallas se deben a la eficacia del método de recuperación, siendo probablemente el resultado de la fracturación de un número relativamente bajo de porciones esqueléticas.

(14) La identificación se ha llevado a cabo con la colección comparativa del Laboratorio de Arqueozoología de la Universidad Autónoma de Madrid y la metodología general es la expuesta en Clason (1972). La estimación de la edad se basa en Morales (1976), excepto en el caso del ciervo (Mariezkurrena, 1983). La osteometría sigue criterios de Driesch (1976) y la adaptación de siglas al castellano de Miguel y Morales (1984).

(15) Otros yacimientos madrileños: 42 ' $4 \%$ en El Ventorro, $54 ' 7 \%$ en La Loma de Chiclana y 28 ' $5 \%$ en El Capricho (Morales y Liesau, 1994). 
Desde un punto de vista tafonómico la muestra es cualitativamente heterogénea (Gautier, 1987), fundamentalmente restos de consumo y de forma minoritaria elementos de industria $(0,1 \% \mathrm{NR})$ y carcasas (0'2\% NR) (16). Entre los ocho taxones documentados, predominan los animales domésti$\cos (88 \%$ del NR) y, en concreto, los ovicaprinos y el vacuno. Les siguen en orden de importancia los suidos, mientras que el perro puede considerarse testimonial. El ciervo (1'4\% NR) es el único mamífero silvestre, aunque dada la dificultad de discriminar los restos de cerdos y jabalíes inmaduros, no puede descartarse la presencia de estos últimos; en este caso han sido asignados a la categoría genérica (Sus $s p$.). Finalmente, resalta la ausencia de conejo, taxón presente en menor o mayor medida en yacimientos de la Prehistoria reciente del área, en muchos casos como elementos intrusivos.

La fauna no aparece homogéneamente distribuida por el área excavada, ni existe relación aparente entre el tamaño muestral y la capacidad de las estructuras. Así, 12 de ellas (35\%) carecen de material faunístico, contando otras 12 con menos de 10 fragmentos identificables (o al menos adscribibles a meso o macrofauna). En las estructuras del suroeste (en especial 2800, 1400, 1900, 3400 y 3500 ) se recuperó algo más del $70 \%$ de los restos identificables. Aquí están también los dos cráneos completos de perro (u.e. 3400 y 1400) y uno de vaca (u.e. 300) (17).

La única carcasa se sitúa en el extremo opuesto (este): un suido inmaduro asociado a la inhumación masculina depositada en la covacha lateral (u.e. 109). Cuenta con paralelos próximos en $\mathrm{La}$ Loma del Lomo (Valiente, 1992), donde las carcasas de suidos inmaduros acompañan a una de las tres inhumaciones masculinas adultas, a ninguna de las cuatro femeninas, y a dos de las 15 infantiles identificadas como masculinas. De los 13 restantes, todos ellos indeterminados, cuatro contaban con esta asociación. Aunque aparentemente significativa, la escasa base inferencial reduce el alcance de cualquier posible valoración de la asociación carcasa de suido inmaduro-inhumación masculina.

(16) La fauna analizada pertenece exclusivamente al área $\mathrm{C}$ Conociendo el abundantísimo $\mathrm{NR}$ recuperados en el área $\mathrm{A}$ (51676 gr.), no consideramos oportuno realizar apreciaciones respecto a la mayor o menor importancia de las cabañas o de la actividad cinegética.

(17) Un paralelo casi idéntico ha sido documentado en la fosa F17 de Moncín (Harrison et alii, 1994: 46), en la que se depositó un cráneo de cabra. Existen también casos similares en el Tejar del Sastre (Quero, 1982) y la Loma del Lomo (Valiente, 1992).
La industria es el tercer grupo de fauna representado en el yacimiento, fabricada tanto sobre soporte óseo como malacológico. Los depósitos de la u.e. 2800 acumulan los dos únicos útiles, un resto de punzón y un fragmento de diáfisis rebajada, ambos sobre metapodio de ovicaprino. Esto contrasta con los 24 punzones contabilizados en las 54 estructuras del área $\mathrm{A}$, lo que puede ser indicativo de la escasa presencia de actividades artesanales o de procesamiento de productos realizados en el área C.

Los tres restos de almeja de río no son adscribibles a ningún grupo tafonómico (Gautier, 1987). En todo caso, no parecen constituir elementos de consumo, debido tanto a su baja frecuencia como a la relativa inaccesibilidad de las poblaciones naturales. No muestran signos claros de su uso potencial y, aun así, constituyen un elemento faunístico constante en los yacimientos del área (Díaz-Andreu et alii, 1992; Morales y Villegas, 1994; Priego y Quero, 1992; Quero, 1982).

La fauna alóctona del yacimiento, un fragmento de 'colmillo de elefante' (Dentalium sp.) recuperado en los depósitos de la u.e. 3500 , podría haberse utilizado como elemento de adorno, hipótesis que avalan tanto sus características morfológicas como su uso continuado como elemento ornamental en la Península Ibérica desde el Paleolítico (Moreno, 1995). Esta pieza indica la existencia de contactos interregionales que, aunque puntuales, son constantes tanto durante el Calcolítico (Martínez Navarrete, 1984) como en toda la Edad del Bronce (Molero, 1987; 1992; Blasco, 1987b).

\section{e. Inhumaciones}

Se han documentado un total de 5 inhumaciones distribuidas en tres estructuras. Su deficiente estado de conservación, con una elevada pérdida de masa ósea como consecuencia de las condiciones externas (humedad, procesos erosivos, etc), exigió la observación in situ de gran parte de los indicadores de sexo y edad de los individuos (18).

(18) La excavación y recogida de datos siguió las indicaciones de McKinley y Roberts (1993) y las recomendaciones del Workshop of European Anthropologists (1980). La identificación de los restos óseos sigue a McMinn et alii (1990), England (1990) y Hillson (1986). Dado el pésimo estado de preservación de los individuos adultos, la edad se estimó principalmente atendiendo a la observación del desgaste dental (Brothwell, 1987). Este método suele utilizarse en combinación con otros por la dificultad de establecer una correlación directa entre desgaste dental y edad. Al resultar imposible dicha contrastación, los individuos del Area C 


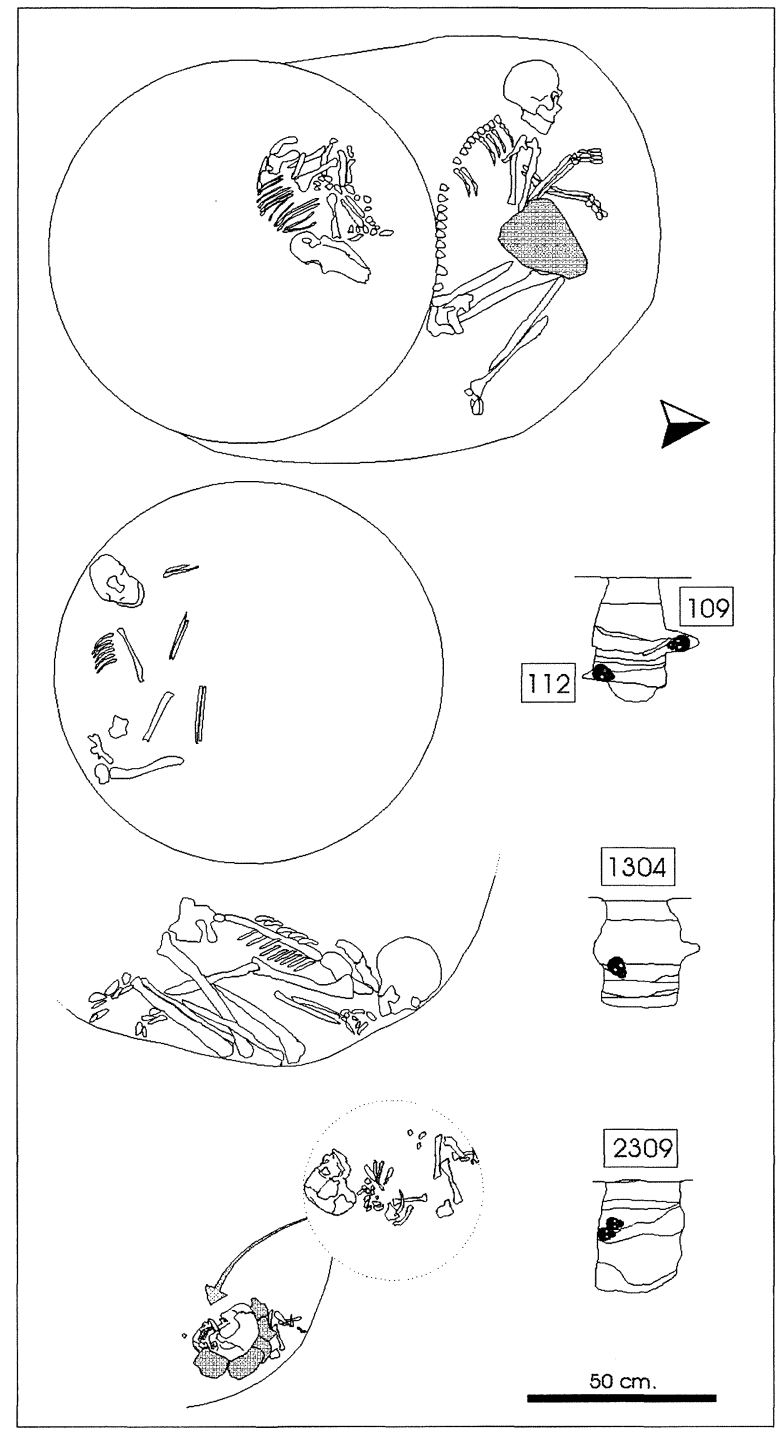

Fig. 6. Disposición de las inhumaciones documentadas en el Area C de 'Las Matillas' (Alcalá de Henares, Madrid).

En la u.e. 100 se recuperaron dos inhumaciones (109 y 112). La superior se disponía en una covacha lateral, excavada en el sector norte de la pared y sellada verticalmente mediante una laja de caliza (19). El individuo fue depositado en posición fetal sobre su lado izquierdo, con la cabeza orientada al oeste. Las piernas se dispusieron cruzadas y

se han agrupado atendiendo a amplias categorías de edad: jóvenes (18-25 años), maduros (26-45) y mayores de 45 (McKinley y Roberts, 1993).

(19) Este tipo de laja puede obtenerse a poco más de $1 \mathrm{~km}$ al sur del yacimiento, en las laderas del cerro del Viso. flexionadas a la altura del abdomen, descansando los brazos ligeramente separados del cuerpo. La colocación de las extremidades, tanto superiores como inferiores, muestra el sumo cuidado con el que se depositó al fallecido, un hombre maduro de constitución grácil pero atlética, dado el fuerte desarrollo muscular observado. Asociada a la inhumación se excavó una carcasa de suido inmaduro perfectamente articulado.

Tres estratos por debajo del anterior aparecieron una serie de huesos extremadamente alterados por la humedad (u.e. 112). La conservación selectiva de algunas regiones anatómicas en conexión indica que el cadáver, una mujer joven, fue depositado en un avanzado estado de descomposición. Dada la posición del cráneo, del que se recuperaron parte de la base junto con la mandíbula y las primeras vértebras cervicales todavía articuladas, parece que el cadáver fue abandonado boca abajo. En las proximidades se identificaron otras partes articuladas del mismo individuo y un molar cuya superficie aparecía posiblemente alterada por el fuego. Las primeras sobrevivieron a la manipulación post-mortem gracias a sus fuertes estructuras ligamentarias: fragmentos costales con sus correspondientes vértebras dorsales, una cavidad cotiloidea con la cabeza del fémur y fragmentos aislados de las diáfisis de extremidades superiores. Dada la ausencia de otro tipo de evidencia de combustión en la estructura, es posible que se deba a algún tipo de manipulación del cadáver cuando éste se hallaba en proceso de descomposición.

La posición estratigráfica indica la anterioridad de la inhumación 112, y por tanto debería admitirse que se trata de una deposición originalmente secundaria. Sin embargo, las características de los depósitos parecen indicar que el individuo fue manipulado post-mortem y desplazado de la covacha para proceder a una nueva inhumación (u.e. 109). Esta hipótesis explicaría la postura deposicional del cadáver 112, así como la presencia de un potente estrato de arena limpia sobre el 109, únicamente extraíble de la interfaz a la cota del individuo 112. En definitiva, es presumible que el individuo 112 se encontrase inicialmente en la covacha lateral y que posteriormente fuera desplazado para enterrar al 109.

El individuo documentado en la u.e. 1304 yacía adaptado a la pared de la estructura, en posición fetal sobre su lado izquierdo y con el cráneo orientado al norte. El brazo izquierdo descansaba doblado y en posición palmar, con la mano relajada y los 
dedos cayendo sobre la palma. El brazo derecho aparecía semiflexionado, recogiendo las piernas con la mano vertical hacia abajo, mientras el pie izquierdo estaba hiperflexionado, postura únicamente posible si se introdujo al cadáver tras el rigor mortis. Las observaciones realizadas en la cintura pelviana y el cráneo indican que posiblemente se trata de una mujer madura de constitución grácil y musculatura desarrollada, que alcanzó aproximadamente una estatura de 1'55 m. (20).

El cadáver fue depositado sobre un estrato de arcilla limpia de unos $8 \mathrm{~cm}$. de potencia media y el cráneo sobre un conjunto de guijarros. Este sedimento fue extraído de las paredes, a juzgar por las oquedades documentadas a la cota de la inhumación, las cuales no presentan las características de una erosión natural. Bajo él, se excavaron dos estratos, el último de ellos compuesto por finos depósitos entremezclados de arenas y arcillas. Este es el probable resultado del lavado de las paredes, durante el lapso de tiempo en que la estructura estuvo a la intemperie antes de rellenarse.

En la u.e. 2390 se documentaron dos inhumaciones infantiles. El conjunto se compone de un primer individuo de unos 9-10 años (21), cuyo cráneo (sin mandíbula) se dispuso cuidadosamente sobre cinco guijarros, y de un niño menor de un año (22) enterrado bajo éstos, en posición fetal con el cráneo orientado al sur. Próximo al primero se localizaron fragmentos deteriorados de una mandíbula y otros restos dispersos, presumiblemente pertenecientes al mismo individuo. Ambos infantes fueron depositados en un único momento y cuando la estructura se encontraba en un proceso avanzado de relleno. Esto evidencia que las inhumaciones de carácter primario y secundario conviven en el tiempo, realizándose incluso de forma simultánea.

Estratigráficamente, todos los casos se asocian a momentos posteriores al abandono de las estructuras. Esto también ocurre en uno de los yacimientos con más documentación funeraria de la zona, La Loma del Lomo (Valiente, 1987; 1992), en el que el $89 \%$ de las inhumaciones descansan sobre estratos intermedios de relleno. Todo ello parece

(20) Para la estimación de la estatura se utilizaron los huesos largos, siguiendo las tablas de regresión de Trotter y Gleser (1958).

(21) La edad se estimó in situ, en base al grado de erupción dental (Ubelaker, 1989)

(22) Tal como indica el grado de fusión de los elementos de la columna vertebral (England, 1990). indicar que ninguna de las estructuras fue excavada con finalidad estrictamente funeraria sino que las inhumaciones se realizaron cuando se encontraban en un avanzado proceso de colmatación.

La presencia en el relleno de la u.e. 1300 de un fragmento de borde decorado, adscribe la inhumación al denominado Bronce 'Clásico' mientras la u.e. 100 y 2300 tienen indicadores cerámicos del Calcolítico tipo 'Esgaravita'. La tipología de las inhumaciones puede encontrarse tanto en momentos avanzados del Calcolítico (Blasco et alii, 1994) como durante la Edad del Bronce (Geanini, 1991; Blasco et alii, 1991; Valiente, 1987; 1992), lo cual deja como única vía la datación absoluta de alguna muestra ósea.

\section{f. Metalurgia}

Se han documentado restos metalúrgicos entre los depósitos de las interfaces 200, 1700 y 2400, identificados con la ayuda de una lupa binocular y análisis cualitativos mediante Espectrometría por fluorescencia de rayos X. A la u.e. 1702 pertenece un fragmento laminar de cobre con ligeras impurezas de antimonio y plata. En la u.e. 203 se recuperó un fragmento de escoria, cuyo análisis visual permite identificar la estructura porosa con matriz silícea característica de este tipo de material, revelando su análisis cualitativo una escasa cantidad de hierro. Por último, la u.e. 2407 contenía un conjunto de pequeños fragmentos cerámicos con adherencias de escoria en su cara interna. Tan solo en uno de ellos se ha podido detectar cobre, aunque en proporción demasiado baja para realizar un análisis cuantitativo fiable. Junto al cobre y hierro, presenta impurezas de antimonio.

Estos restos no sugieren una actividad metalúrgica espacialmente inmediata, máxime conociendo el potencial registro resultante de este tipo de producción (Quero y Priego, 1992). La presencia minoritaria, tanto de productos elaborados como de residuos de producción, permite considerarlos como probable resultado de una incorporación accidental a los depósitos.

\section{g. Restos botánicos}

A pesar del volumen de sedimento procesado por flotación, la mayoría de los estratos proporcionaron un número muy reducido de semillas, con bajas densidades y algunos casos estériles. Única- 
mente destacan los depósitos de las interfaces 100 y 800 , la primera por contener la mayor cantidad de semillas y la segunda por documentar una pequeña acumulación de cereales. Las especies identificadas incluyen tanto plantas domésticas (cereales) como silvestres.

La cebada y el trigo son los únicos cereales documentados, ambos componentes fundamentales en la agricultura prehistórica europea, destacando su deficiente estado de conservación en comparación con las especies silvestres recuperadas.

La presencia de cereal está atestiguada en las estructuras independientemente de su capacidad. La especie de trigo identificada se engloba en la categoría de Triticum aestivum/durum, que incluye tanto especies tetraploides como hexaploides (23) (depósitos de u.e. 100, 500, 800, 1200 y 1300). Hay escasos restos de cebada (Hordeum L.): cariópsides (depósitos de u.e. 500, 700 y 1300) y un fragmento de raquis (Hordeum $s p$.) (depósito de u.e. 500).

Gran parte de la muestra corresponde a especies silvestres de diversas familias (quenopodiáceas, crucíferas, leguminosas, etc), en su mayoría plantas adventicias, aquellas que habitualmente acompañan a los cultivos. Este es el caso de las papaveráceas (Glaucium corniculatum, Papaver sp.), boragináceas (Myosotis arvensis), quenopodiáceas (Chenopodium sp., Atriplex sp.) o leguminosas (Astragalus sp., Medicago sp., Trigonella sp.). Destaca por su abundancia el Sisymbrium, especialmente recurrente en algunas de las muestras de la u.e. 100, en las que supera el millar de semillas, tratándose de una crucífera propia de campos de cultivo, campos abandonados y bordes de caminos.

Los datos sobre agricultura prehistórica del área son prácticamente nulos dada la ausencia de estudios arqueobotánicos, por lo que resulta imposible realizar un análisis comparativo. Aunque tan solo 8 muestras de las 112 analizadas han proporcionado cereales, es evidente que los habitantes del yacimiento desarrollaban procesos agrícolas. Entre los hallazgos especiales destaca la muestra obtenida de la base de la u.e. 800 , constituida por una pequeña concentración de cereales (58 cariópsides). La ausencia de malas hierbas en esta estructura podría explicarse como consecuencia de la

(23) En material arqueológico, y ante la ausencia de restos de espiga (raquis), resulta difícil distinguir ambas especies. Por ello habitualmente las cariópsides de trigos desnudos se clasifican de este modo. limpieza del cereal previo almacenaje y por tanto, podría ser un indicador de este tipo de proceso agrario. La quema de las paredes en silos subterráneos tras la extracción del grano es una práctica frecuente y altamente eficiente, anulando gran parte de la microflora perjudicial para posteriores almacenajes (Reynolds, 1988). Esta puede dar como resultado pequeños estratos con semillas carbonizadas como el documentado (24).

La llegada accidental de vegetales a las estructuras, como restos incorporados al relleno, parece la propuesta mas viable. Son varias las razones que refuerzan esta propuesta: su escasez, el carácter ruderal de la mayoría de las especies y su distribución dispersa en el relleno sin concentraciones aparentes. La pauta esperable en un entorno de habitación es la frecuencia de restos vegetales carbonizados, como resultado de la gran variedad de actividades llevadas a cabo. Independientemente de su incorporación al sedimento de forma accidental, existen numerosos modos de llegada, como el procesado de las plantas para su consumo como alimento u otros fines (medicinales, condimentos, tintes, ornamentales...), la construcción y acondicionamiento de las casas (techados, suelos, lechos...), combustibles o alimentación animal. En el caso del Area C, la pobreza de la muestra, tanto cerámica, faunística como botánica, refuerza la hipótesis de que nos encontremos ante una zona no utilizada como hábitat.

\section{LA ORGANIZACIÓN DEL ESPACIO AGRARIO}

La valoración comparativa presenta notables diferencias entre las áreas excavadas (A y C). Sin embargo, las características de este tipo de yacimientos generan un conjunto de problemas que limitan la potencial obtención de conclusiones.

Los resultados del área $C$ indican que las posibilidades de una adscripción cronológica a partir de los restos cerámicos está seriamente limitada, tanto por las clasificaciones morfotipológicas tradicionales como por los procesos de formación del registro arqueológico. Admitiendo que los restos pudieron estar expuestos a la intemperie durante un tiempo previo a su deposición definitiva en las subestructuras, es presumible considerar que no

(24) Una interpretación similar han recibido los restos botánicos recuperados en la Fosa F93 de Moncín (Wetterstrom, 1994: 494).

T. P., 54, n. $^{\circ} 2,1997$ 
remiten necesariamente a un momento contemporáneo a su colmatación. Frente a esta indeterminación, la dispersión, volumen y fragmentación de los restos pueden ser útiles indicadores del tiempo transcurrido hasta su incorporación al registro arqueológico, relativizando o reforzando el grado de fiabilidad de las adscripciones cronológicas. Junto a ello, la distribución espacial de las interfaces, valoradas en función de su capacidad y procesos erosivos, pueden ser indicadores de un uso prolongado del espacio que haga comprensible la variabilidad cronológica de los restos recuperados.

El segundo problema parte de la ausencia de estratos horizontales que permitan vincular los rellenos de las estructuras a actividades desarrolladas en el entorno. Según Bradley y Fulford (1980: 90), existen dos modelos posibles a la hora de analizar la relación entre áreas de actividad e índices de fragmentación cerámica: la tendencia a depositar los desechos domésticos en las proximidades del lugar de procesamiento de productos, asociado a una menor fragmentación y su desplazamiento fuera del mismo, lo que implica una mayor fragmentación en las áreas de mayor actividad. Los dos yacimientos analizados por los autores confirmaban una relación directa entre mayores fragmentos y proximidad a las viviendas, conclusión reforzada por los análisis de fosfatos.

En nuestro caso hemos seleccionado junto con los índices de fragmentación cerámica las siguientes variables: capacidad y distribución de las estructuras, características del sedimento en función de la presencia/ausencia de materia orgánica, dispersión, concentración y volumen de residuos. Analizados en su conjunto, todos los resultados revelan una serie de elementos comunes al área $\mathrm{C}$, destacando su acusada diferencia respecto a las documentadas en A:

- Las capacidades totales de las interfaces presentan una distribución no aleatoria. Las de mayor volumen se disponen en la periferia del área, dejando espacios 'exteriores' sin evidencias arqueológicas. Al contrario, el área A cuenta con una distribución aparentemente caótica. Todo ello parece indicar una compartimentación cultural y productiva del espacio socialmente transformado. Desde una lectura arqueogeográfica, la disposición del área $\mathrm{C}$ podría ser conceptualizada como un elemento orgánico de organización del espacio agrario, entendido como 'frontera' o 'límite' entre el hábitat y el espacio potencialmente ocupado por el ager (Vicent, 1991: 41).
- No existe vinculación directa entre la capacidad de las estructuras y la densidad de restos, ni entre las dos áreas, ni en cada una de ellas consideradas de forma independiente. Frente a la alta densidad de restos cerámicos, líticos y óseos con un bajo índice de fragmentación del área $\mathrm{A}$, el área $\mathrm{C}$ presenta un perfil contrario: baja densidad de restos y alto índice de fragmentación. Esto implica que, utilizando como epicentro el área A, el desplazamiento hacia el 'exterior' se resuelve en una reducción considerable de densidad, frecuencia y tamaño de restos.

- Las estructuras del área $\mathrm{C}$ presentan escasos indicadores arqueológicos que presupongan actividades de transformación doméstica, siendo viable la incorporación accidental al sedimento de la mayor parte de los restos materiales recuperados. La disposición de las mismas debe responder a actividades que no generen o requieran procesamiento doméstico alguno. Las únicas evidencias contrarias son la acumulación de escasos restos faunísticos en un reducido espacio del área excavada, así como la presencia de gran parte de la cadena operativa lítica. En este segundo caso, y dado que no es presumible el excesivo desplazamiento de restos líticos de escasas dimensiones, debe admitirse que una de las actividades desarrolladas implicaba la transformación y uso del sílex. En el área $\mathrm{A}$, tanto las características sedimentológicas de los depósitos como el volumen de restos asociables a actividades domésticas permiten suponer la proximidad de espacios de transformación, tanto de materias primas como de productos.

No siendo lugar para defenderla detalladamente, la hipótesis más parsimoniosa pasa por interpretar la mayor parte de las estructuras documentadas como lugares de almacenaje subterráneo a largo plazo. Sobre ellos existe una amplia documentación experimental (Reynolds, 1974; 1979; 1988), etnográfica (Gast y Sigaut, 1979; 1981; Gast et alii, 1985) e histórica (p.e. Plinio, Historia Natural; Tácito, Germania, 16.4), siendo la propuesta mayoritariamente refrendada por los arqueólogos peninsulares (p.e. Maya, 1985; Fernández Ugalde, 1994; Harrison et alii, 1994; Bellido, 1996). Entre las evidencias estratigráficas del área C, contamos con la acumulación de cereal carbonizado de la u.e. 800. Sin embargo, la más concluyente es la propia presencia de estructuras interfaciales formalmente idénticas a los silos subterráneos y en los cuales «els períodes representats pels interfaces frecuentment es referixen a 
períodes de temps molt més llargs que els necessaris per construir els dipòsits sota aqueste superfícies» (Harris, 1992: 105).

La distribución no caótica del yacimiento indica un uso prolongado del espacio, así como la existencia de 'barreras' o límites que bien podrían responder a la definición de áreas de explotación agraria. A partir de la evidencia experimental y etnográfica podemos evaluar aproximadamente el tiempo transcurrido entre el inicio y finalización del uso de este espacio de almacenaje. El cereal es el único producto almacenable detectado, calculándose el volumen para un consumo anual de diez adultos en una media de 10001 . Las 12 estructuras de mayor tamaño serían capaces de mantener a 160 adultos durante un ciclo agrario, siempre que su uso fuese simultáneo. Calculando la vida media de un silo en diez años (Reynolds, 1988: 111), y presuponiendo una población de 20 adultos, este espacio pudo haber sido utilizado como área de almacenaje durante más de 80 años.

Todos los indicios recuperados en el yacimiento permiten considerar que el área $\mathrm{C}$ responde a un espacio de producción y reproducción del ciclo agrario, destacándose una compartimentación socialmente institucionalizada respecto a aquellos dedicados fundamentalmente a la transformación y el consumo. La inversión de fuerza de trabajo en áreas no habitacionales, generando una estructuración del espacio productivo, transforma este trabajo en lo que en términos analógicos podría denominarse 'capital fijo' de la comunidad campesina (Gilman y Thornes, 1985: 188; Vicent, 1991: 62).

Junto a ello, la asociación de enterramientos a espacios productivos, y en particular a estructuras de almacenaje amortizadas, muestra un panorama distinto del tradicionalmente asumido por la investigación. Mientras gran parte de las inhumaciones documentadas en otros yacimientos se asociaban a áreas de vivienda (p.e. Valiente, 1987; 1992), persistían una serie de estructuras funerarias dispersas que, dada la poca extensión de las excavaciones, se convertían en referentes para demostrar la incesante movilidad de los grupos prehistóricos (p.e. Blasco et alii, 1994).

Entendido en términos históricos, la presencia de inhumaciones en el interior de los poblados evidenciaría el cambio de un patrón de relaciones míticas con los antepasados, característico de las bandas, por otro de relaciones genealógicas. En él, y mediante las inhumaciones, los familiares justifican tanto la existencia del grupo social en el presente como su apropiación del espacio habitacional. Siendo viable esta interpretación, las inhumaciones en áreas productivas indicarían como la 'justificación ideológica' va más allá de la reivindicación del área habitacional, extendiéndose a la apropiación genealógica del territorio productivo, dentro del cual el silo concentra toda la significación de un paisaje ya domesticado.

En definitiva, 'capital fijo' y apropiación refuerzan la importancia de los medios de producción inmóviles como determinantes primordiales de las relaciones de producción (Díaz-del-Río, 1995: 104).

\section{PERSPECTIVAS}

Gran parte del registro del III y II milenios a.C. de la Meseta se caracteriza por la presencia casi continua de los denominados yacimientos de 'fondos de cabaña'. A pesar del elevado número de intervenciones, aumentadas en los últimos años por las exigencias legales, el conocimiento de la estructura social que genera este tipo de formación arqueológica sigue siendo escaso. En último término, esto podría llevar a considerar que la aparente opacidad del registro fuese realmente endémica.

El planteamiento analítico desarrollado en 'Las Matillas' abre camino a una futura clasificación de los yacimientos y a su estructuración interna en función de su uso social. La opción contraria sería excesivamente simplista, exigiendo defender la excepcionalidad del patrón observado.

Sin embargo, las perspectivas abiertas no se reducen a la identificación de áreas de actividad dentro de los yacimientos. La distribución espacial de 'puntos arqueológicos' calcolíticos y de la Edad del Bronce en el área se caracteriza por la casi absoluta presencia de restos superficiales a lo largo de las cuencas fluviales (Almagro y Benito, 1993; Muñoz, 1993; Presas, 1996; Román y Díaz-delRío, 1996). Muchos de ellos se identifican por la escasez de evidencias y su proximidad a lo que podrían denominarse 'áreas de acumulación' (Méndez, 1994). Extrapolar el registro de 'Las Matillas' permite comprender un patrón de poblamiento determinado por la diversidad en el uso del espacio, en el que la reiterada actividad de dos milenios tiende a apropiarse de la naturaleza hasta tal punto que hábitat y ager se solapan y diluyen, formando un paisaje socialmente domesticado.

T. P., 54, n. ${ }^{\circ} 2,1997$ 
La etiqueta de homogeneidad tradicionalmente concedida a gran parte del poblamiento de la Prehistoria reciente en la Meseta conlleva una inconsciente negación de la racionalidad económica en el uso del suelo, producto de una lectura normativa que reduce la Historia a una secuencia tecnotipológica. Sea o no cierta nuestra interpretación, lo relevante del caso es que un planteamiento basado en el análisis de la diversidad es capaz de establecer unas primeras diferencias en la organización y uso del territorio durante el III y II milenios a.C. en áreas de elevada potencialidad agraria. Para ello, cuantificación y evaluación crítica de la superficie excavada se convierten en elementos indispensables.

\section{AGRADECIMIENTOS}

La Dirección General de Patrimonio Cultural de la Comunidad de Madrid extendió permiso y supervisó los trabajos de excavación que aquí presentamos. Agradecemos especialmente el espíritu de colaboración mostrado por la propiedad del solar, en las personas de D. Jesús González y D. Gonzalo Martínez. La analítica de los restos metalúrgicos ha sido realizada gracias a la desinteresada colaboración de Ignacio Montero Ruiz. Los análisis del Laboratorio de Arqueozoología se encuadran dentro del Proyecto PB 94-0186 de la DGICYT. La financiación de la analítica ha corrido a cargo de Trabajos de Arqueología y Restauración S.L. El texto se ha visto favorecido por los comentarios de $\mathbf{M}^{\mathrm{a}}$ Isabel Martínez Navarrete, Arturo Morales Muñiz y Juan M. Vicent García.

\section{BIBLIOGRAFÍA}

Almagro, M. y Benito-LóPez, J.E. (1993): «La prospección arqueológica del valle del Tajuña. Una experiencia teórico-práctica de estudio territorial en la Meseta». Complutum, 4: 297-310.

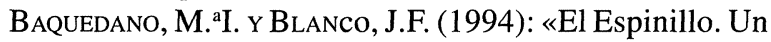
yacimiento importante de la Edad del Bronce en Madrid». Revista de Arqueología, 155: 12-23.

Bellido Blanco, A. (1996): Los campos de hoyos. Inicio de la economía agrícola en la submeseta norte. Studia Archaeologica, 85. Universidad de Valladolid.

Blasco, M. ${ }^{\mathrm{a} C}$. (1987a): «El Bronce Medio y Final». 130 Años de Arqueología Madrileña. Comunidad de Madrid: 83-119.

- (1987b):«Un ejemplar de fíbula de codo ‘ad occhio’ en el Valle del Manzanares». Boletín de la Asociación Española de Amigos de la Arqueología, 23: 18-28.

Blasco, M. ${ }^{a}$ C.; Sánchez-Capilla, M. ${ }^{a} L$. y Calle, J. (1994): «El mundo funerario». En M. ${ }^{a} \mathrm{C}$. Blasco (ed.): El horizonte campaniforme de la región de Madrid en el Centenario de Ciempozuelos. Universidad Autónoma de Madrid. Madrid: 75-99.

Blasco, M. ${ }^{\mathrm{a} C}$.; Sánchez-Capilla, M. ${ }^{a} L$.; Calle, J.; RoBles, F.J.; GonZÁleZ, V.M. y GonZÁleZ, A. (1991): «Enterramientos del horizonte protocogotas en el Valle del Manzanares». Cuadernos de Prehistoria y Arqueología de la Universidad Autónoma de Madrid, 18: 55-112.

Bradley, R. y Fulford, M. (1980): «Sherd size in the analysis of occupation debris». Bulletin of the Institute of Archaeology, 70: 85-94.

BRothwell, D.R. (1987): Desenterrando huesos. La excavación, tratamiento y estudio de restos del esqueleto humano. Fondo de Cultura Económica. México.

Clason, A.T. (1972): «Some remarks on the use and presentation of archaeozoological data». Helinium, XII: 139-153.

Díaz-Andreu, M.; Liesau, C. y Castaño, A. (1992): «El poblado calcolítico de La Loma de Chiclana (Vallecas, Madrid). Excavaciones de urgencia realizadas en 1987». Arqueología, Paleontología y Etnografía, 3: 31-116. Comunidad de Madrid.

DíAZ-DEL-Río, P. (1995): «Campesinado y gestión pluriactiva del ecosistema: un marco teórico para el análisis del III y II milenios a.C. en la Meseta Peninsular». Trabajos de Prehistoria, 52 (2): 99-109.

DíAZ-DEL-Río, P. y SÁNCHEZ, A.L. (1988): «Contribución al conocimiento del Calcolítico del valle del río Henares: el yacimiento de 'La Esgaravita' (Alcalá de Henares)». I Encuentro de Historiadores del Valle del Henares (Guadalajara, 1988): 177-186. Torrejón de Ardoz.

DRIESCH, A. von den (1976): The measurement of bones archaeological sites. Peabody Museum. Yale.

England, M. (1990): A colour atlas of life before birth. Normal fetal development. Wolfe Medical Publications. Aylesbury.

FERnÁNDEZ UgALde, A. (1994): «El fenómeno del relleno de silos y la implantación del feudalismo en Madrid y en el reino de Toledo». Asociación Española de Arqueología Medieval (ed.): IV Congreso de Arqueología Medieval Española (Alicante, Octubre 1993), III: 611-617. Alicante.

Gast, M. y Sigaut, F. (eds.) (1979): Les techniques de conservation des grains à long terme. Leur rôle dans la dynamique des systèmes de cultures et des sociétés, 1. CNRS. París.

- (1981): Les techniques de conservation des grains à long terme. Leur rôle dans la dynamique des systèmes de cultures et des sociétés, 2. CNRS. París.

Gast, M.; Sigaut, F. y Beutler, C. (eds.) (1985): Les techniques de conservation des grains à long terme. Leur 
rôle dans la dynamique des systèmes de cultures et des sociétés, 3 (1 y 2). CNRS. París.

Gautier, A. (1987): «Taphonomic groups: How and why?». Archaeozoologia, I (2): 47-52.

Geanini, A. (1991): «Enterramiento de la Edad del Bronce en la Presa del Rey». Arqueología, Paleontología y Etnografía, 1: 13-29. Comunidad de Madrid.

Gilman, A. y Thornes, J.B. (1985): Land-use and Prehistory in South-East Spain. George Allen \& Unwin. Londres.

Harris, E.C. (1991): Principios de estratigrafía arqueológica. Crítica. Barcelona.

- (1992): «L'Estratigrafia és el matrix de l'Arqueologia». En G. Trócoli y R. Sospedra (eds.): Harris $M a-$ trix. Sistemes de registre en Arqueologia, 1. Estudi General de Lleida, Colección El Fil d'Ariadna, Serie Historia. Pàges Editors: Lleida. 85-107.

Harrison, R.J.; Moreno, G.C. y LegGe, A.J. (1994): Moncín: un poblado de la Edad del Bronce (Borja, Zaragoza). Colección de Arqueología, 16. Diputación General de Aragón. Zaragoza.

Hillson, S. (1986): Teeth. Cambridge University Press. Cambridge.

MARIEZKURRenA, K. (1983): «Contribución al conocimiento del desarrollo de la dentición y el esqueleto postcraneal de Cervus elaphus». Munibe, 35 (3-5): 149-202.

Martínez NAVArRete, M. ${ }^{a} I$. (1979): «El yacimiento de La Esgaravita (Alcalá de Henares, Madrid) y la cuestión de los llamados 'fondos de cabaña' del valle del Manzanares». Trabajos de Prehistoria, 36: 83-118.

- (1984): «El comienzo de la metalurgia en la provincia de Madrid: la cueva y cerro de Juan Barbero (Tielmes, Madrid)». Trabajos de Prehistoria, 41: 17-91.

- (1987): «Los primeros períodos metalúrgicos». 130 Años de Arqueología Madrileña: 58-81. Comunidad de Madrid.

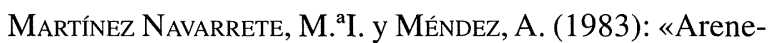
ro de Soto. Yacimiento de 'fondos de cabaña' del horizonte Cogotas I». Estudios de Prehistoria y Arqueología Madrileñas, 2: 183-254.

MAYA, J.L. (1985): «Silos de la Primera Edad del Hierro en la Universidad Autónoma de Barcelona». Estudios de la Antigüedad, 2: 147-230.

McKinley, J.I. y RoberTs, C. (1993): «Excavation and post-excavation treatment of cremated and inhumed human remains». Technical Paper, 13. Institute of Field Archaeologists. Birmingham.

McMinn, R.M.; Hutchings, R.T. y Logan, B.M. (1990): The human skeleton: a photographic manual. Wolfe Medical Publications. Londres.

MÉNDEZ FERnÁNDEZ, F. (1994): «La domesticación del paisaje durante la Edad del Bronce gallego». Trabajos de Prehistoria, 51 (1): 77-94.

Miguel, F.J. y Morales, A. (1984): «Catálogo para la unificación de medidas del esqueleto postcraneal de los mamíferos en España». Primeras Jornadas de Metodología de Investigación Prehistórica. Soria (1981). Ministerio de Cultura. Madrid: 299-305.

Molero, G. (1987): «Anexo V. Estudio de los restos faunísticos del yacimiento de 'El Lomo' de Cogolludo (Guadalajara)». En J. Valiente: La Loma del Lomo I. Cogolludo, Guadalajara. Excavaciones Arqueológicas en España, 152: 187-191.

- (1992): «Estudio de los restos óseos de la zona B del yacimiento de 'El Lomo' de Cogolludo (Guadalajara)». En J. Valiente: La Loma del Lomo II. Patrimonio Histórico-Arqueología. Junta de Comunidades de Castilla-La Mancha. Guadalajara: 273-286.

Morales, A. (1976): Contribución al estudio de las faunas mastozoológicas asociadas a yacimientos prehistóricos españoles. Tesis Doctoral. Universidad Complutense. Madrid.

Morales, A. y Villegas, C. (1994): «La fauna de mamíferos del yacimiento de 'El Ventorro': síntesis osteológica de la campaña de 1981". Estudios de Prehistoria y Arqueología Madrileñas, 9: 35-56.

' Moreno, R. (1995): «Arqueomalacofaunas de la Península Ibérica: un ensayo de síntesis». Complutum, 6: 353382.

MuÑoz, K. (1993): «El poblamiento desde el Calcolítico a la Primera Edad del Hierro en el valle medio del río Tajo». Complutum, 4: 321-336.

Presas Vías, M. (1996): «Carta Arqueológica del Término Municipal de Villarejo de Salvanés». Reunión de Arqueología Madrileña S.C. (eds.): Reunión de Arqueología Madrileña: 298-291. Madrid.

Priego, C. y Quero, S. (1992): «El Ventorro, un poblado prehistórico de los albores de la metalurgia». Estudios de Prehistoria y Arqueología Madrileñas, 8. Madrid.

QuERo, S. (1982): «El poblado del Bronce medio de Tejar del Sastre (Madrid)». Estudios de Prehistoria y Arqueología Madrileñas, 1: 185-241.

Reynolds, P.J. (1974): «Experimental Iron Age storage pits: an interim report». Proceedings of the Prehistoric Society, 40: 118-131.

- (1979): «A general report of underground grain storage experiments at the Butser Ancient Farm Research Proyect». En M. Gast y F. Sigaut (eds.): Les techniques de conservation des grains à long terme. Leur rôle dans la dynamique des systèmes de cultures et des sociétés, 1. CNRS. Paris: 70-80.

- (1988): Arqueologia experimental. Una perspectiva de futur. Eumo Editorial. Vic.

Román, L. y DíAz-DEL-Río, P. (1996): «Carta Arqueológica del T.M. de Camarma de Esteruelas». Reunión de Arqueología Madrileña S.C. (eds.): Reunión de Arqueología Madrileña: 292-293. Madrid.

Shennan, S. (1992): Arqueología Cuantitativa. Crítica. Barcelona.

Soto, E. (1983): «Análisis de los restos faunísticos del yacimiento de 'fondos de cabaña' de Getafe». Estu-

T. P., 54, n. $^{\circ} 2,1997$ 
dios de Prehistoria y Arqueología Madrileñas: 277. 284.

SPENCE, C. (1992): «Archaeological site manual». En I.G. Trócoli y R. Sospedra (eds.): «Harris Matrix. Recording systems in Archaeology». 1. El Fil d'Ariadna. Estudi General de Lleida, Sèrie Història. Lleida: 124-252.

Tringham, R.; CoOPer, G.; Odell, G.; Voytek, B. y WhitMAN, A. (1974): «Experimentation in the formation of edge damage: a new approach to the lithic analysis». Journal of Field Archaeology, 1: 171-196.

Trotter, M. y Glesser, G. (1958): «Re-evaluation of stature based on measurements taken during life and on long bones after death». American Journal of Physical Anthropology, 16 (1): 79-123.

UBELAKER, D. (1989): Human skeletal remains, excavation, analyses, interpretation. Smithsonian Institution. Washington D.C.

Valiente Malla, J. (1987): La Loma del Lomo I. Excavaciones Arqueológicas en España, 152. Ministerio de Cultura. Madrid.

- (1992): La Loma del Lomo II. Patrimonio HistóricoArqueología. Junta de Comunidades de Castilla-La Mancha. Guadalajara.

VAUGHAN, P. (1985): Use-wear analysis of flaked stone tools. University of Arizona Press. Tucson.

VEGA, J.J. (1996): «Excavación arqueológica de urgencia realizada en Complutum, Alcalá de Henares, Madrid (Sector Carretera de Circunvalación)». Reunión de Arqueología Madrileña S.C. (eds.): Reunión de Arqueología Madrileña: 142-144. Madrid.

Velasco, F. (1992): «Un modelo de gestión a partir de la declaración de zonas arqueológicas amplias: el caso de Madrid». Jornadas Internacionales de Arqueología de Intervención (San Sebastián, 1991). Centro de Patrimonio Cultural Vasco: 75-83. Guipuzcoa.

VICENT, J.M. (1991): «Fundamentos teórico-metodológicos para un programa de investigación arqueo-geográfica». En P. López (ed.): El cambio cultural del IV al II milenios a.C. en la comarca noroeste de Murcia. Consejo Superior de Investigaciones Científicas. Madrid: 29-117.

VILLES, A. (1981): «Les silos de l'habitat protohistorique en Champagne Crayeuse». En M. Gast y F. Sigaut (eds.): Les techniques de conservation des grains à long terme. Leur rôle dans la dynamique des systèmes de cultures et des sociétés, 2. CNRS. París: 194-213.

Wetterstrom, W. (1994): «Plantas Carbonizadas. Carbonized Plant Remains». En R.J. Harrison, G.C. Moreno y A.J. Legge: Moncín: un poblado de la Edad del Bronce (Borja, Zaragoza). Colección de Arqueología, 16. Diputación General de Aragón. Zaragoza: $483-$ 508. 